\title{
Risk of predation and food consumption by black-tailed jackrabbits
}

WILLIAM S. LONGLAND

\begin{abstract}
Vegetation cover may afford many species of prey animals reduced risk of being detected and/or attacked by predators. In this study, feeding stations were provided for black-tailed jackrabbits (Lepus californicus) at 3 distances from perennial shrubs to test the prediction that the intensity of foraging by these hares would subside as they moved away from the presumed safety of shrub cover. Jackrabbits consumed significantly more food at stations under shrub canopies than at stations 5 and $10 \mathrm{~m}$ from shrubs. Thus, results are consistent with the hypothesis that risk of predation constrains the foraging activities of jackrabbits. The two-fold increase in food consumption near shrubs as compared with consumption away from shrubs implies that native plants or agronomic crops should incur lower levels of herbivory by jackrabbits when they occur at some distance from protective cover.
\end{abstract}

Key Words: Lepus californicus, foraging, herbivory, shrub cover

Herbivory by black-tailed jackrabbits (Lepus californicus), which frequently attain high local densities in the western and plains states, may constitute an important impact on productivity of native range, range restoration projects, or agronomic crops. Some studies have concluded that feeding by these hares has a detrimental effect on crops or range plants (Sparks 1968, Flinders

\footnotetext{
Author is ecologist, USDA-ARS, University of Nevada, 920 Valley Road, Reno 89512 . Ur " " ". " " " of Rangelands anonymous reviewers for comments on earlier drafts of the manuscript. Manuscript accepted 22 November 1990.
}

and Hansen 1972, Rumbaugh and Pedersen 1979, Fagerstone et al. 1980), while in other cases even peak jackrabbit populations have been reported to have a negligible effect on local vegetation (Fautin 1946, Westoby and Wagner 1973, Roundy et al. 1985). However, a common thread in these and other studies is that jackrabbit densities and/or plant damage from herbivory are greatest in areas providing cover near the food source. In this context "cover" generally refers to any vegetation feature large enough to render animals inconspicuous when sitting motionless. Thus, young plant growth and low-growing grasses, forbs, or crops lack cover, but established tall grasses, shrubs, or taller crops may provide good cover.

A growing body of literature, including studies of grey squirrels (Sciurus carolinensis: Lima and Valone 1986, Newman and Caraco 1987, Newman et al. 1988), hoary marmots (Marmota caligata: Holmes 1984), and desert rodents (Kotler 1984, Brown 1988), demonstrates that herbivorous or granivorous small mammals often concentrate their feeding activities in areas providing nearby vegetation or rock cover, avoiding areas with little or no cover. Typically, in these studies, foraging subsides as a food source is moved further from cover, producing an inverse correlation between food consumption and distance from cover. Such results may indicate that foraging activities of small mammals are constrained by the risk of being preyed upon, since cover is generally assumed to provide protection from predators and predation risk is therefore assumed to increase with distance from cover. 
Indeed, these assumptions have been verified in the case of owl predation on desert rodent prey; great horned owls (Bubo virginianus) have higher attack and capture rates on rodents foraging away from shrub cover than on those foraging beneath or near shrubs (Longland 1989, Longland and Price 1991).

Black-tailed jackrabbits are preyed upon by a variety of predators, including coyotes (Canis latrans: Wagner and Stoddart 1972, MacCracken and Hansen 1987, personal observation), bobcats (Lynx rufus: Delibes and Hiraldo 1987), and birds of prey (Johnson 1954, Korschgen and Stuart 1972). Although predators constitute a major source of mortality in some populations of jackrabbits (Wagner and Stoddart 1972) or congeneric hare species (Smith et al. 1988), their role in limiting jackrabbit densities is probably variable in space and/or time. However, predators can alter the behavior of individual prey as well as densities of prey populations (Kotler and Holt 1989), so regardless of the impact of predatorinflicted mortality on jackrabbit populations, the simple fact that jackrabbits are commonly preyed upon suggests that their behavior may be affected by predation risk.

There is some evidence suggesting that foraging activities of lagomorphs, including jackrabbits, are sensitive to predation risk. For example, pikas (Ochotona princeps) do not stray far from the cover of the rock pile they occupy, and their feeding activities produce a "grazing gradient" in local vegetation as they forage selectively for particular food plants in a manner that is dependent on their distance from the rock pile (Huntly et al. 1986, Huntly 1987). Similar gradients are associated with rabbit grazing, presumably due to reduced feeding activity with increasing distance from the protective cover of burrows or shrubs (Farrow 1917, Gillham 1955, Bartholomew 1970). Indirect evidence suggests that jackrabbits may show such behavior as well. Studies by Fautin (1946) and Lechleitner (1958) showed that although jackrabbits foraged predominantly in open grasslands, their highest densities were in adjacent areas providing vegetation cover. Westoby and Wagner (1973) and McAdoo et al. (1987) found that numbers of jackrabbit droppings decreased from the edges to the centers of large rangeland seedings, presumably because less foraging occurred as distance from cover at seeding edges increased. McAdoo et al. (1987) speculated that this may be at least partly due to predation risk increasing with distance from cover. However, in spite of the conspicuousness of jackrabbits relative to many other small mammals, and their potential economic importance, there have been no experimental studies on the relationship between feeding activities of these hares and proximity to protective cover.

Here I describe results of an experiment in which food was supplied for black-tailed jackrabbits at feeding stations that varied in proximity to shrub cover. This allowed a direct test of the prediction that jackrabbit food consumption would decrease as a food source is moved away from cover. From the results of this experiment, I draw implications regarding effects of predation risk on jackrabbit foraging behavior, and how this may in turn affect the success of agricultural activities in areas subject to jackrabbit herbivory.

\section{Methods}

The experiment was conducted for 15 nights between 17 January and 8 February 1989 in a rural residential area $6 \mathrm{~km}$ NW Reno, Nevada (T20N, R19E, S17). Black-tailed jackrabbits occurred in high densities at this time, due possibly to the presence of several food sources (hay piles) at houses while food availability in surrounding undeveloped land was reduced by heavy snow cover. Vegetation on undeveloped land in the area consisted primarily of 3 Great Basin shrub species: Wyoming big sagebrush (Artemisia tridentata wyomingensis), bitterbrush (Purshia tridentata), and green rabbitbrush (Chrysothamnus viscidiflorus).
Three jackrabbit "feeders" were placed singly under the canopies of randomly selected shrubs. I placed 2 additional feeders in open spaces as near as possible to each shrub-feeder location such that 1 feeder was $5 \mathrm{~m}$ and the second $10 \mathrm{~m}$ from the nearest shrub. Thus, I used 3 groups of feeders (i.e., blocks), each group consisting of 3 feeders (i.e., treatments) which differed in proximity to shrubs, for each trial of the experiment. Each feeder, constructed of a shallow tin dish nailed to the center of a 30- by 30-cm plywood square, was stocked with $100 \mathrm{~g}$ of pressed alfalfa rabbit pellets at dusk on nights of experimental trials, and any remaining pellets were collected at dawn the following morning and weighed. Because the only tracks observed in snow around the feeders came from jackrabbits, I assumed that they accounted for all food consumption.

For analysis, the mass of pellets removed from each feeder was converted to the proportion removed of the original $100 \mathrm{~g}$. These proportions were arcsin-transformed and used as the dependent variable in an ANOVA with blocks, experimental trial dates, and proximity of feeders to shrubs as independent variables. A "trial date $X$ feeder location" interaction term was also included in this ANOVA. Although a crucial assumption of ANOVA-homogeneity of variances among treatment groups-was satisfied by the transformed data, a second assumption (Sokal and Rohlf 1981) - that the data are normally distributed - was violated. Therefore, I conducted a second ANOVA in which the amount of food consumed was summed for the 3 replicate feeders at each distance from shrubs, and this was converted to the proportion of the total $300 \mathrm{~g}$ available at each distance on each trial date. After arcsintransformation, these proportions were normally distributed and had homogeneous variances among treatments. This second ANOVA was similar to the first, except that interaction terms had to be omitted from the model because the original blocks were eliminated by combining treatment data across replicates. Thus, in the latter model, experimental trial dates became the blocking variable (Sokal and Rohlf 1981). I ran Duncan's multiple range tests in conjunction with each of these ANOVAs (SAS ANOVA procedure-SAS Institute Inc. 1987) to test for differences in food consumption among individual treatment groups (i.e., feeder locations).

\section{Results}

The ANOVA model that included replicated blocks of feeders revealed a significant effect of blocks $(F=16.25$, d.f. $=2,88$, $P<0.0001)$, trial dates $(F=3.14$, d.f. $=14,88, P<0.0005)$, and feeder locations relative to shrub cover $(F=21.09$, d.f. $=2,88, P<0.0001)$ on food consumption by jackrabbits. However, the "trial date $X$ feeder location" interaction was not significant $(F=1.30$, d.f. $=$ $28,88, P>0.18$ ), indicating that the effect of feeder locations was similar over time. Although the second ANOVA (with data combined across replicate blocks) also included a significant "feeder location" term $(F=13.36$, d.f. $=2,28, P<0.0001)$, the effect of trial date in this model was not significant $(F=0.01$, d.f. $=14,28$, $P>0.99)$. Thus the significant "date" effect in the first ANOVA must be due either to the departure of the full data set from normality, or to the replicated blocking design with its associated inflation of degrees of freedom.

Consistent with the hypothesis that jackrabbits reduce their feeding as they move away from cover, mean proportions of rabbit pellets consumed per night were inversely related to distance of feeders from shrubs (Fig. 1). Duncan's multiple range tests performed on the data in the above ANOVAs indicated that significantly more food was consumed from feeders near shrubs than from those 5 or $10 \mathrm{~m}$ away from shrubs $(P<0.05)$. However, the difference in food consumption between feeders $5 \mathrm{~m}$ and $10 \mathrm{~m}$ from shrubs was not significant. In the ANOVA with data combined across blocks, feeder location accounted for practically all (48.7\%) 


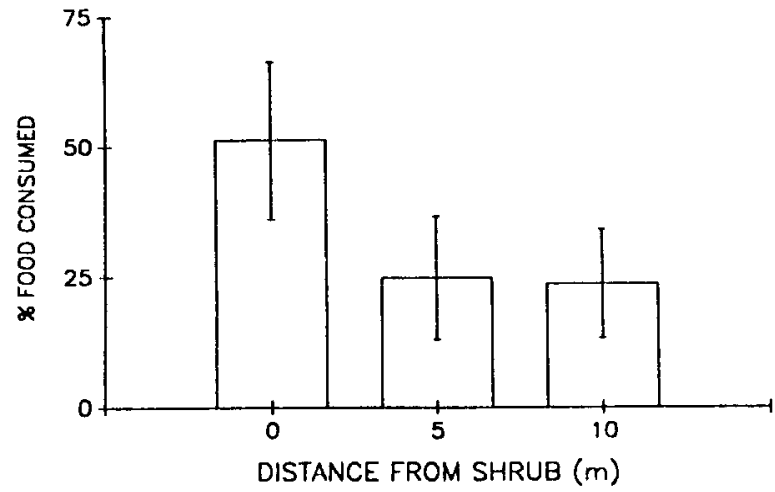

Fig. 1. Mean percentages ( \pm SD) of available food (i.e., rabbit pellets) consumed by black-tailed Jackrabbits at 3 distances from shrub cover. Food consumption was significantly higher near shrubs $(0 \mathrm{~m})$ than away from shrubs (5 and $10 \mathrm{~m})$.

of the variance in food consumption explained by the entire model $\left(r^{2}=0.490\right)$.

\section{Discussion}

Results of this experiment demonstrate that foraging by blacktailed jackrabbits subsides as the animals move away from shrub cover. The decrease in food consumption at feeders away from shrubs may be due to decreased feeding by individual animals at these feeders, or to fewer animals in the jackrabbit population using these feeders. I suspect that the former explanation is at least partially responsible, first because feeders at different distances from shrubs were in close proximity, and therefore equally detectable for jackrabbits, and secondly because I observed that jackrabbits appeared to be more vigilant when feeding away from shrub cover. Vigilance during foraging has been documented in various animals, and is probably directed at reducing predation risk (Lima 1987). Foraging European rabbits (Oryctolagus cuniculus), for example, exhibit increased levels of vigilance when predation risk increases (Roberts 1988).

Jackrabbits reduced their consumption of food by approximately one-half in open spaces relative to shrub-site feeders. McAdoo et al. (1987) found that jackrabbit utilization of rangeland seedings $5 \mathrm{~m}$ from shrub cover was similar to or more than utilization in nearby shrub-covered habitat. The apparent discrepancy between the latter results and those of the present study may stem in part from the use of an indirect index of jackrabbit utilization (i.e., dropping counts) by McAdoo et al., but is probably due more to differences between native habitat and seedings in the relative availability of food plants. The present study, which used a direct index of food consumption and equal food availability at all feeder locations, should provide a more precise indication of the effects of cover on food consumption by jackrabbits.

The reduction in jackrabbit feeding intensity that occurs away from shrub cover has implications for the success of agricultural operations in jackrabbit-inhabited areas. For example, rangeland seedings with complete shrub removal are likely to suffer less herbivory from jackrabbits than those with partial removal. It may be possible to reduce both the costs of seeding and the degree of herbivory by leaving an unseeded "bare zone" around the perimeter of fields bordered by shrub habitat. Such bare zones occur naturally in California, where they are established by severe herbivory in ecotonal areas between chaparral and grassland habitats (Bartholomew 1970). After they are established, these bare zones reduce the intensity of rabbit herbivory in the grassland because rabbits are hesitant to venture from the cover provided in chapar- ral. If bare zones were intentionally left at the time a field is seeded, they should reduce the initial herbivory that occurs around the perimeter. However, a potential drawback is that bare zones may also allow the invasion of undesirable noxious weeds.

It may be prudent in some cases (such as when seed for the target crop is quite expensive) to seed an inexpensive "decoy" plant species at the shrub border that is attractive to jackrabbits. Of course, these suggestions are most likely to be practical only under special circumstances: at times of high jackrabbit population densities or at particularly vulnerable periods of plant growth, such as early in the germination and establishment processes, for example. Although some herbivory must be expected virtually anytime that agricultural operations are attempted in areas where jackrabbits occur, results of this study imply that it should be possible to at least reduce the potential damage from these herbivores. Fruitful areas for future research would be quantitative studies of effects of partial vs. complete brush removal on jackrabbit feeding intensity and effects of boundary bare zones or "decoy" jackrabbit food plants on productivity of target plant species under various jackrabbit population densities.

The intensity of jackrabbit foraging did not decrease consistently with distance from shrubs. Food consumption levels were similar between feeders located $5 \mathrm{~m}$ and $10 \mathrm{~m}$ from cover (Fig. 1). Perhaps for prey species such as jackrabbits and other hares which evade predators by fleeing rather than seeking shelter, shrub cover primarily affects risk by decreasing the probability of being detected by a predator; the probability of actually being captured by a predator following detection may differ negligibly between sites $5 \mathrm{~m}$ and $10 \mathrm{~m}$ from shrub cover. It seems likely, however, that risk would increase substantially at much larger distances from shrubs because it would take a fleeing animal some time to reach the distant cover, and shrub cover should interfere with a pursuing predator's ability to track its prey visually and to maneuver. This may explain why jackrabbit utilization of crested wheatgrass seedings subsided at large distances $(\geq 100 \mathrm{~m})$ from shrub cover in studies by Westoby and Wagner (1973) and McAdoo et al. (1987).

The fact that jackrabbit food consumption did not differ significantly between feeders 5 and $10 \mathrm{~m}$ from shrubs implies that an alternative explanation, other than predation risk, may account for the significantly higher food consumption under shrubs. Perhaps shrub-feeder locations were preferred because jackrabbits loose less radiant heat to the environment when partly sheltered by shrubs than when feeding in open spaces. If conservation of body heat is the reason that feeding subsided away from shrub cover, there are potentially important consequences concerning jackrabbit herbivory. Specifically, the reduction in jackrabbit feeding intensity away from protective cover would occur mainly during cold weather and would not be expected to persist into warmer seasons when plant growth occurs. However, there is some evidence which refutes this alternative explanation.

First, although this study was conducted during winter, nighttime minimum temperatures ranged between $-27^{\circ} \mathrm{C}$ and $-1^{\circ} \mathrm{C}$. The tendency for animals to prefer shrub-covered feeders might be expected to vary with the severity of the low temperature if heat conservation affects foraging site preferences. However, this was apparently not the case; the "trial date $\times$ feeder location" interaction term (from ANOVA) was not significant, indicating that shrub feeders were preferred similarly on all trials nights. As a more powerful test of the potential effect of temperature on site preferences, I ran an analysis of covariance (ANCOVA) substituting minimum nightly temperature (the covariate) for the "trial date" variable that was used in the ANOVA. After confirming the homogeneity of slopes for effects of experimental treatments and minimum temperatures on jackrabbit food consumption, the ANCOVA revealed that minimum temperature had no significant 
effect on food consumption $(F=1.10$, d.f. $=1,131, P>0.29$ ), but feeder location (adjusted for covariation in minimum temperature) still had a highly significant effect $(F=13.87$, d.f. $=2,131$, $P<0.0001$ ).

A second bit of evidence arguing against the idea that jackrabbits forage preferentially near shrubs primarily as a means to reduce heat loss comes from the studies of Westoby and Wagner (1973) and McAdoo et al. (1987). The latter study was conducted during warm seasons (late spring-summer), and the former utilized counts of jackrabbit droppings that had apparently accumulated over at least a one-year period. Thus, neither of these studies was restricted to periods of cold weather, yet in both cases jackrabbits utilized shrub-covered sites more than open seedings, and jackrabbit abundance indices diminished as distance from shrub cover increased.

I conclude, then, that the most likely explanation for blacktailed jackrabbits to prefer foraging near cover is that their behavior is sensitive to predation risk. The foraging-site preferences of these hares should reduce depredation of low-growing plants which do not provide adequate cover, such as rangeland seedings and many crops. It remains to be seen whether jackrabbit foraging behavior is flexible to the extent that they reduce food consumption with incremental increases in predation risk, but there is evidence of such behavioral plasticity in predator avoidance for the European rabbit (Jaksić and Soriguer 1981). If so, then it may be possible to ameliorate jackrabbit herbivory by enhancing local densities of their predators through, for example, provisioning of roosting sites for birds of prey or bait stations for mammalian carnivores.

\section{Literature Cited}

Bartholomew, B. 1970. Bare zone between California shrub and grassland communities: the role of animals. Science 170:1210-1212.

Brown, J.S. 1988. Patch use as an indicator of habitat preference, predation risk, and competition. Behav. Ecol. Sociobiol. 22:37-47.

Delibes, M., and F. Hiraldo. 1987. Food habits of the bobcat in two habitats of the southern Chihuahuan desert. Southwest. Natur. 32:457-461.

Fagerstone, K.A., G.K. Lavoie, and R.E. Grimth, Jr. 1980. Black-tailed jackrabbit diet and density on rangeland and near agricultural crops. J. Range Manage. 33:229-233.

Farrow, E.P. 1917. On the ecology of the vegetation of Breckland. III. General effects of rabbits on the vegetation. J. Ecol. 5:1-18.

Fautin, R.W. 1946. Biotic communities of the northern desert shrub biome in western Utah. Ecol. Monogr. 16:251-310.

Flinders, J.T., and R.M. Hansen. 1972. Diets and habitats of jackrabbits in northeastern Colorado. Colorado State Univ. Range Sci. Dep. Sci. Ser. No. 12.

Gillham, M.E. 1955. Ecology of the Pembrokeshire Islands. III. The effects of grazing on the vegetation. J. Ecol. 43:172-206.

Holmes, W.G. 1984. Predation risk and foraging behavior of the hoary marmot in Alaska. Behav. Ecol. Sociobiol. 15:293-301.
Huntly, N.J. 1987. Influence of refuging consumers (pikas: Ochotona princeps) on subalpine meadow vegetation. Ecology 68:274-283.

Huntly, N.J., A.T. Smith, and B.L. Ivins. 1986. Foraging behavior of the pika (Ochotona princeps), with comparisons of grazing versus haying. J. Mammal. 67:139-148.

Jaksic, F.M., and R.C. Soriguer. 1981. Predation upon the European rabbit (Oryctolagus cuniculus) in Mediterranean habitats of Chile and Spain: a comparative analysis. J. Anim. Ecol. 50:269-281.

Johnson, N.K. 1954. Food of the long-eared owl in southern Washoe County, Nevada. Condor 56:52.

Korschgen, L.J., and H.B. Stuart. 1972. Twenty years of avian predatorsmall mammal relationships in Missouri. J. Wildl. Manage. 36:269-282.

Kotler, B.P. 1984. Risk of predation and the structure of desert rodent communities. Ecology 65:689-701.

Kotler, B.P., and R.D. Holt. 1989. Predation and competition: the interaction of two types of species interactions. Oikos 54:256-260.

Lechleitner, R.R. 1958. Certain aspects of the behavior of the black-tailed jackrabbit. Amer. Midl. Natur. 60:145-155.

Lima, S.L. 1987. Vigilance while feeding and its relation to the risk of predation. J. Theor. Biol. 124:303-316.

Lima, S.L., and T.J. Valone. 1986. Influence of predation risk on diet selection: a simple example in the grey squirrel. Anim. Behav. 34:536-544.

Longland, W.S. 1989. Risk of predation and microhabitat choice by heteromyid rodents. Ph.D. Diss., Univ. California, Riverside.

Longland, W.S., and M.V. Price. 1991. Direct observations of owls and heteromyid rodents: can predation risk explain microhabitat use? Ecology 72:(In Press).

MacCracken, J.G., and R.M. Hansen. 1987. Coyote feeding strategies in southeastern Idaho: optimal foraging by an opportunistic predator? J. Wildl. Manage. 51:278-285.

McAdoo, J.K., W.S. Longland, G.J. Cluff, and D.A. Klebenow. 1987. Use of new rangeland seedings by black-tailed jackrabbits. J. Range Manage. 40:520-524.

Newman, J.A., and T. Caraco. 1987. Foraging, predation hazard and patch use in grey squirrels. Anim. Behav. 35:1804-1813.

Newman, J.A., G.M. Recer, S.M. Zwicker, and T. Caraco. 1988. Effects of predation hazard on foraging "constraints": patch-use strategies in grey squirrels. Oikos 53:93-97.

Roberts, S.C. 1988. Social influences on vigilance in rabbits. Anim. Behav. 36:905-913.

Roundy, B.A., G.J. Cluff, J.K. McAdoo, and R.A. Evans. 1985. Effects of jackrabbit grazing, clipping, and drought on crested wheatgrass seedlings. J. Range Manage. 38:551-555.

Rumbaugh, M.D., and M.W. Pedersen. 1979. Survival of alfalfa in five semiarid range seedings. J. Range Manage. 32:48-51.

SAS Institute, Inc. 1987. SAS/STAT guide for personal computers, version 6 edition. Cary, N.C.

Smith, J.N.M., C.J. Krebs, A.R.E. Sinclair, and R. Boonstra. 1988. Population biology of snowshoe hares. II. Interactions with winter food plants. J. Anim. Ecol. 57:269-286.

Sokal, R.R., and F.J. Rohlf. 1981. Biometry. W.H. Freeman and Co., San Francisco.

Sparks, D.R. 1968. Diet of black-tailed jackrabbits on sandhill rangeland in Colorado. J. Range Manage. 21:203-208.

Wagner, F.H., and L.C. Stoddart. 1972. Influence of coyote predation on black-tailed jackrabbit populations in Utah. J. Wildl. Manage. 36:329-342.

Westoby, M., and F.H. Wagner. 1973. Use of a crested wheatgrass seeding by black-tailed jackrabbits. J. Range Manage. 26:349-352. 